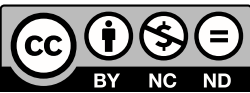

Estudos Teológicos foi licenciado com uma Licença Creative Commons Atribuição - NãoComercial - SemDerivados 3.0 Não Adaptada

http://dx.doi.org/10.22351/etv59i2.3541

\title{
A prática da ConfirmaÇão entre Anglicanos Brasileiros: INCOERÊNCIAS E DESAFIOS ${ }^{1}$
}

\author{
The practice of Confirmation among Brazilian Anglicans: \\ incoherencies and challenges
}

\section{Luiz Carlos Teixeira Coelho Filho J. Neil Alexander ${ }^{3}$}

\begin{abstract}
Resumo: Este artigo busca discutir a natureza e a origem da Confirmação no anglicanismo e como tal tradição foi transferida às pessoas anglicanas no Brasil. Também enfatiza algumas inconsistências que surgiram da dicotomia entre os ensinamentos oficiais e novas teologias do Livro de Oração Comum, e práticas corriqueiras, as quais ainda são influenciadas por costumes antigos e pela prática de igrejas cristãs maiores. Por fim, algumas propostas são apresentadas, de modo a guiar liturgistas, comissões e sínodos à medida que a Igreja Episcopal Anglicana do Brasil (IEAB) segue adiante no discernimento do significado do Batismo como iniciação plena e do papel da Confirmação como endosso de tal visão.

Palavras-chave: Confirmação. Anglicanos. Brasil. Desafios.
\end{abstract}

Abstract: This article intends to discuss the nature and origin of Confirmation in Anglicanism and how this tradition was handed over to Brazilian Anglicans. It also emphasizes some incoherencies that have arisen from the dichotomy between official teachings and new Book of Common Prayer theologies and ordinary practices, which are still influenced by ancient customs and by the practice of other larger Christian churches. Finally, some proposals are presented which could guide liturgists, commissions and synods as the Igreja Episcopal Anglicana do Brasil (IEAB) moves forward discerning the meaning of Baptism as full initiation and the role of Confirmation in endorsing this view.

Keywords: Confirmation. Anglicans. Brazil. Challenges.

1 O artigo foi recebido em 12 de dezembro de 2018 e aprovado em 07 de agosto de 2019 com base nas avaliações dos pareceristas ad hoc.

2 Mestre. The University of the South, Sewanee, Tennessee, Estados Unidos. E-mail: coelhlc0@sewanee.edu

3 Doutor. The University of the South, Sewanee, Tennessee, Estados Unidos. E-mail: deansot@sewanee.edu 


\section{Introdução}

A prática da Confirmação entre a população anglicana brasileira sempre foi consideravelmente desafiadora. As dimensões gigantescas do país e a falta de igrejas paroquiais ou missões na maior parte do país durante a primeira metade do século XX fizeram com que os bispos muitas vezes tivessem que viajar longas distâncias para confirmar e receber novos membros. Histórias românticas sobre bispos viajando de barco ou embarcando em pequenos aviões para sobrevoar a Amazônia são bastante comuns. ${ }^{4}$ De certa forma, o conceito de receber a visita de um(a) bispo(a) para confirmar e receber novos membros tornou-se profundamente arraigado e estabelecido na mentalidade da pessoa anglicana/episcopal brasileira média.

No entanto, sua evolução vis-à-vis o movimento litúrgico e os desenvolvimentos teológicos no século XX deixou várias questões por resolver. Se o Batismo é visto pelo Livro de Oração Comum atual como um sacramento de iniciação total no corpo de Cristo, qual é o papel da Confirmação e por que algumas paróquias ainda obrigam as crianças a esperar até a Confirmação para receber Comunhão? Se um(a) bispo(a) é requerido(a) em Confirmações, por que a IEAB apenas recebe (sem confirmar) pessoas oriundas da tradição católico-romana ou ortodoxa? Se a Confirmação é verdadeiramente uma afirmação madura da fé, por que pessoas das tradições luterana, metodista e presbiteriana são obrigadas a fazer tudo de novo se quiserem se tornar anglicanas?

Este artigo procura explicar como tais (e outras) questões evoluíram ao longo dos anos, examinando brevemente como a Confirmação se desenvolveu enquanto rito distinto na cristandade ocidental e por que ela se tornou tão especial para o anglicanismo. Ele também aponta as principais inconsistências entre uma interpretação desatualizada de seu papel e visões atuais da centralidade do Batismo e das relações ecumênicas, e sugere algumas mudanças na prática para melhor.

\section{Uma breve história da Confirmação na vida da igreja: do começo ao início da Idade Média}

Invariavelmente, a maioria das igrejas cristãs demandará um processo de iniciação à vida em Cristo para as pessoas que escolheram seguir a Jesus (ou cujos responsáveis e/ou parentes o fizeram em seu nome). Johnson ${ }^{5}$ nos lembra que os ritos cristãos de iniciação geralmente seguem um padrão quádruplo consistindo de:

\footnotetext{
4 Algumas publicações sobre a história do anglicanismo na Amazônia, por exemplo, citam como o Revmo. Edmund Knox Sherrill, então bispo do Brasil Central (que cobria quase todos os estados brasileiros) viajava para os Estados Unidos para a Convenção Geral via conexão em Manaus, para que ele pudesse parar a caminho dos EUA e visitar a comunidade ali.

5 JOHNSON, Maxwell E. The Rites of Christian Initiation. Collegeville: Liturgical Press, 2007. p. 18.
} 
(1) Entrada no Catecumenato, um rito de separação;

(2) o Catecumenato e eventual "eleição" para a iniciação, um tempo "liminar" de transição e preparação, durante o qual as pessoas a serem iniciadas são instruídas e formadas no ensino e vida da comunidade;

(3) os Ritos de iniciação (Batismo, "Confirmação" e Primeira Comunhão), pelos quais pessoas que passaram pelo catecumenato, agora "eleitas" são agora incorporadas completamente na vida da comunidade cristã; e

(4) o Período de Mistagogia (“explicação dos mistérios"), um processo contínuo de incorporação ou reintegração na comunidade, explicando o que os "mistérios" recebidos significam e quais são suas implicações para a vida em andamento na comunidade.

Sobre o que Johnson geralmente descreve como "(3) os ritos de iniciação", $\operatorname{Senn}^{6}$ aponta para alguns elementos litúrgicos comuns: "o próprio banho de água; unção antes e depois do banho; a imposição de mãos com oração pelo dom do Espírito Santo; primeira comunhão".

Esse padrão básico surgiu muito cedo na história da igreja, por várias razões. A separação entre o Batismo e a Confirmação como dois ritos isolados e separados (que ainda é a norma entre muitas igrejas ocidentais), no entanto, levou muito mais tempo para ser totalmente desenvolvida. O testemunho bíblico da igreja primitiva, como encontrado nas Escrituras, indica o Batismo como o único rito de iniciação cristã, herdado de uma linha direta de continuidade prática advinda de João Batista, Jesus e das comunidades cristãs originárias. Por exemplo, a história de Cornélio, que foi batizado com toda a sua casa (Atos 10.1-11,18) e do eunuco etíope, cujo Batismo foi um ato consciente de fé (Atos 8.26-40). Esses Batismos provavelmente foram por imersão, e tão livres quanto possível em termos de cerimonial e ritual. Não há indicação de ritos adicionais, mas isso não significa que eles não existissem. $\mathrm{O}$ que permanece incontestado foi que, por meio do Batismo, essas pessoas foram feitas parte do corpo de Cristo.

A aclamação trinitária (eu te batizo em nome do Pai, Filho e Espírito Santo) tornou-se a norma eventualmente, mas foi precedida (pelo menos em alguns casos) por um Batismo em nome de Jesus (Atos 8.14-17). Às vezes, seria seguido por um rito de imposição de mãos, interpretado em relação ao dom do Espírito Santo. ${ }^{7}$ Isso mostra claramente um padrão evolutivo e diferente das práticas batismais seguidas por João - e possivelmente outras pessoas -, que meramente tratavam do arrependimento dos pecados. Não existe uma ligação clara e direta entre essa imposição de mãos do rito (com a invocação do Espírito Santo) e a Confirmação na igreja ocidental, mas o ato de impor as mãos tornou-se um sinal poderoso do chamado do Espírito, que, é claro, foi usado mais tarde nas práticas de Confirmação.

Nos quarto e quinto séculos, um padrão mais unificado começou a surgir entre as comunidades cristãs. Uma unção pré-batismal começou a ser associada principalmente ao exorcismo e foi acompanhada por elaboradas cerimônias que lidavam com a

\footnotetext{
SENN, Frank. Introduction to Christian Liturgy. Minneapolis: Augsburg Fortress, 2012. p. 157.

JOHNSON, 2007, p. 29.
} 
renúncia ao pecado e a preparação para uma vida cristã. Uma segunda unção, depois do Batismo, foi gradualmente associada ao dom do Espírito Santo. ${ }^{8}$ Essa segunda unção usaria óleo de crisma. "Morte e sepultamento em Cristo" (conceito teológico tirado de Romanos 6) tornou-se um padrão amplamente usado, que substituiu as antigas teologias baseadas no Batismo de Jesus no Jordão e o novo nascimento na água e no Espírito (João 3). ${ }^{9}$

No Ocidente surgiu o conceito de "Confirmação", em documentos como o Concílio de Elvira, o Primeiro Concílio de Toledo, o Primeiro Concílio de Arles e o Primeiro Concílio de Orange. ${ }^{10}$ Tais concílios, que ocorreram na Espanha e na Gália, introduziram um rito complementar de imposição de mãos e unção com crisma, a ser feito pelo bispo, em casos específicos, tais como: reconciliação de hereges com a igreja (que era um tema controverso na época, especialmente no norte da África) e sempre que os Batismos eram realizados sem unção com crisma, como Batismos de emergência, ou simplesmente quando não havia óleo disponível na igreja! ${ }^{11}$

Em Roma, no entanto, o papel do bispo tomou um rumo inteiramente peculiar. Era o único lugar no mundo cristão onde o bispo era obrigado a impor as mãos sobre os recém-batizados e realizar uma segunda unção. Ao contrário de outros lugares no Ocidente, onde uma "Confirmação" episcopal era uma exceção, em Roma era a norma. Um bispo precisava estar presente, em todos os momentos, para confirmar as pessoas após o Batismo. Com o passar do tempo, isso evoluiria para um sacramento específico e rito separado, que será examinado na próxima seção.

\section{A emergência da Confirmação como rito em separado}

Ao longo da Idade Média, a igreja ocidental iria gradualmente abraçar a prática litúrgica romana, que influenciou como a Confirmação veio a ser vista no Ocidente. O Sacramentário Gelasiano e Ordo Romanus XI apontam para um conjunto muito específico de rituais após o Batismo. ${ }^{12}$ Primeiro, o presbítero faria o sinal da cruz com crisma, na fronte na pessoa batizada (que, na maioria dos casos, era um bebê) e uma oração que ligava o Batismo à salvação em Cristo através da regeneração (João 3). Depois disso, o bispo impunha suas mãos sobre a fronte de cada pessoa, invocando os sete dons do Espírito e finalmente ungindo com óleo de crisma. Se a unção pré-batismal fosse contada, um total de três unções aconteceria num Batismo na Roma Medieval. Ordo XI referia-se à segunda oração de imposição de mãos com unção explicitamente como "confirmação" e enfatizou-a como obrigatória. ${ }^{13}$

\footnotetext{
8 DEISS, Lucien. Springtime of the Liturgy. Collegeville: Liturgical Press, 1967. p. 202-203.

9 JOHNSON, 2007, p. 156.

${ }^{10}$ FERGUSON, Everett. Baptism in the Early Church: History, Theology, and Liturgy in the First Five Centuries. Grand Rapids: Eerdmans, 2013. p. 663-668

11 JOHNSON, 2007, p. 180-182.

12 SENN, 2012, p. 161.

13 JOHNSON, 2007, p. 227-228.
} 
O principal problema com a adoção dos costumes romanos era a dificuldade de ter um bispo presente em todo e qualquer Batismo em dioceses que cobriam grandes áreas, vagamente povoadas. Em Roma, sempre havia uma infinidade de bispos que presidiam em igrejas diferentes, então nunca houve um problema. ${ }^{14}$ Mas em outros lugares, as dioceses cobriam vastas áreas geográficas e dificuldades de transporte, guerras e clima severo muitas vezes impediam aos bispos estar em todas as celebrações da iniciação cristã. Alcuíno de Iorque, escrevendo no século IX, deixou claro que sacerdotes poderiam comunicar os recém-batizados sem serem confirmados pelo bispo com crisma. ${ }^{15}$ Era uma medida prática que acabaria por se tornar a norma. A Confirmação passou a ser adiada até que um bispo estivesse disponível, e os recém-batizados poderiam receber a comunhão antes de receber a prece com imposição de mãos (e unção) de um bispo.

Um entendimento teológico diferente também começou a emergir para essa ação litúrgica distinta. Quando o escolasticismo se tornou a linha de pensamento quase oficial da igreja ocidental, teólogos medievais passaram a lutar a fim de descobrir um lugar para a Confirmação na vida da igreja. Eles não podiam dissociar o Batismo do Espírito Santo, mas tinham que encontrar um significado para esse outro rito que não era mais realizado imediatamente após o Batismo. ${ }^{16}$ Tomás de Aquino finalmente selaria a discussão distinguindo o Batismo como uma fonte de vida nova e regeneração espiritual, da Confirmação como um fortalecimento adicional no Espírito Santo e atestaria que este último deveria ser recebido "na idade madura da vida espiritual" 17 , sendo o crisma (óleo) a matéria sacramental apropriada para a Confirmação. Uma teologia da Confirmação como fortalecimento e do óleo de crisma como uma questão essencial para a ação sacramental foi posta em prática.

Neste ponto, o Catecumenato foi reduzido a um mero conjunto de questões litúrgicas, reduzindo ao mínimo a preparação batismal. Como a maioria dos recém-batizados eram bebês, sua preparação real foi adiada e muitas vezes negligenciada, deixando espaço para questionamentos sobre a "idade da razão" apropriada para receber a Comunhão e receber Confirmação por um bispo. No final da Idade Média, o Batismo, a Confirmação e a Primeira Comunhão, originalmente três ações unificadas que ocorriam na mesma celebração litúrgica, haviam se tornado três coisas separadas, acontecendo em diferentes momentos da vida de uma criança. O Batismo infantil seria realizado por um sacerdote local e ocorreria o mais cedo possível; estava ligado principalmente a conceder a salvação da condenação eterna, purificar a criança do pecado original e exorcizar o bebê do poder de Satanás logo no início da vida, o que era visto como extremamente importante numa época em que as taxas de mortalidade eram absurdas. Um curto período de catequese, seguido pela primeira confissão e primeira comunhão, aconteceria aos sete anos de idade, antes da Confirmação. Tudo

\footnotetext{
14 FERGUSON, 2013, p. 768-769.

15 JOHNSON, 2007, p. 251.

${ }^{16}$ AUSTIN, Gerard. Anointing With the Spirit: The Rite of Confirmation, the Use of Oil and Chrism. Collegeville: Liturgical Press, 1985. p. 17.

17 JOHNSON, 2007, p. 254.
} 
isso era feito no nível local, por um padre. A Confirmação, que seria obrigatoriamente realizada por um bispo, foi cada vez adiada para uma idade de sete anos ou mais (posteriormente, passou à adolescência), vindo a acontecer claramente depois da primeira comunhão. Ela estava ligada ao fortalecimento no Espírito Santo para a vida cristã, mas muitas pessoas acabavam por não ser confirmadas. Tal padrão, com pequenas modificações, influenciaria as abordagens católicas romanas dos ritos de iniciação até o século XX. ${ }^{18}$

No Oriente, pelo contrário, o Batismo, os ritos pós-batismais associados ao Espírito Santo (isto é, a Crisma) e a Primeira Comunhão permaneceram como um único rito unificado, um padrão que permanece até hoje. ${ }^{19}$

\section{A Reforma inglesa e a Confirmação}

Os reformadores trataram, em geral, de simplificar os ritos batismais e de confirmação de seus múltiplos ornamentos adicionados durante toda a Idade Média. Quando se trata, especificamente, da Reforma inglesa, deve-se notar que existem diferenças consideráveis entre os Livros de Oração Comum (LOC) cranmerianos de 1549 e o de 1552 (que deu o tom para o LOC de 1662). O rito batismal do LOC 1549 manteve uma série de costumes de épocas anteriores. O rito de 1552 era muito mais reformado em sua essência. ${ }^{20}$ Não continha exorcismos nem uma bênção da pia batismal. Nenhuma referência à unção de pessoas batizadas antes ou depois do Batismo existia, mas um sinal da cruz a ser feito na cabeça do bebê foi transferido de antes do banho para depois, com uma oração pós-batismal acrescentada, pedindo a Deus que regenerasse a criança e a recebesse como "de Deus", por adoção. ${ }^{21}$

Os reformadores, no entanto, não tiveram tanto interesse em suprir a lacuna que existia entre o Batismo e a Confirmação. O rito de Confirmação de Cranmer era, essencialmente, o mesmo que precedeu a Reforma, embora reinterpretado sob princípios protestantes. Não apresentava uma unção (que era uma tendência entre os reformadores), mas mantinha a imposição das mãos. Era claramente uma maneira para adolescentes marcarem a conclusão da catequese $\mathrm{e}^{22} \mathrm{e}$ passou a preceder a primeira comunhão, que, no caso anglicano, foi cada vez mais adiada para depois de uma Confirmação na adolescência.

No entanto, é injusto afirmar que esse entendimento de Confirmação surgiu sem qualquer reflexão teológica. Houve muita resistência vinda de puritanos e de membros mais reformados da igreja da Inglaterra. Por exemplo, para William Perkins, a Confirmação não tinha base bíblica e, portanto, não tinha natureza sacramental. A imposição das mãos não era mais do que uma oração sobre a pessoa e era realizada pelo bispo simplesmente porque o bispo era o presidente normal da liturgia. Richard

\footnotetext{
18 AUSTIN, 1985, p. 23.

19 JOHNSON, 2007, p. 304.

20 TOVEY, Philip. Anglican Confirmation 1662-1820. Oxford: Routlege, 2014. p. 32-33.

21 TURRELL, James F. Celebrating the Rites of Initiation. New York: Church Publishing, 2013. p. 2.

22 TURRELL, 2013, p. 3.
} 
Hooker, por outro lado, adotou uma visão consideravelmente diferente, alegando que "os Padres da Igreja consideravam a confirmação como apostólica" e que a Confirmação de um bispo era "pertinente à dignidade dos superiores". Ao mesmo tempo, apontou que não era um sacramento, chamando-a de complemento sacramental. ${ }^{23}$ Jeremy Taylor levantou o ponto de que toda a igreja precisava de Confirmação (ainda que não a tratasse como um sacramento de per si), pois, sem ela "somos apenas bebês em Cristo"24. Ele também insistia que os bispos eram os únicos ministros da Confirmação, e até mesmo sugeriu a restauração da unção com crisma. Seus argumentos usavam bastante o conceito de selo: na Confirmação, colocamos "nosso selo à profissão, e Deus coloca seu selo para a promessa [...] recebemos o Espírito Santo como [...] selo de nossa salvação" ${ }^{25}$.

No entanto, é possível salientar que a Confirmação, após a Reforma inglesa e até o século XX, foi claramente reaproveitada como um rito destinado a pessoas que estavam dispostas a fazer uma afirmação madura da fé, com específica imposição de mãos por um bispo. A presença episcopal permaneceu incontestável, pois os bispos eram vistos como aqueles que davam todo tipo de bênção desde a era apostólica. Mas a Confirmação não era vista pela maioria como um sacramento. Tornara-se claramente uma espécie de "cerimônia de formatura" para a catequese de adolescentes rumo à vida adulta, com o benefício de permitir que pessoas recém-confirmadas recebessem a comunhão.

\section{Confirmação entre pessoas anglicanas no Brasil, até o LOC 1984}

Até 1984, todos os livros de oração comum em português eram traduções quase literais de livros norte-americanos. Portanto esses livros de oração claramente mantinham uma compreensão da Confirmação como uma afirmação madura da fé que preparou o caminho para a comunhão na vida da igreja.

No entanto, houve muitos desafios para tal entendimento. Primeiro de tudo, algumas partes do país estavam tão distantes de bispos diocesanos que os mesmos poderiam passar anos sem visitar igrejas locais, de modo que, em muitos lugares, pessoas adultas batizadas - mas ainda sem serem confirmadas - eram membros de fato em plena comunhão e comunicantes. Além disso, em muitas comunidades, pessoas oriundas do catolicismo romano não eram vistas como tendo uma clara compreensão do Batismo, a menos que passassem por um período de catequese e de Confirmação (ou recepção) e poderiam não ter permissão para receber a Comunhão até serem confirmadas. Isso, naturalmente, decorre do fato de muitos dos primeiros missionários pertencerem à ala evangélica da Igreja Episcopal, mas também mostra o quão infrequente a Confirmação (e até a Comunhão) poderia ser. ${ }^{26}$

${ }^{23}$ TURRELL, 2013, p. 51.

${ }^{24}$ TURRELL, 2013, p. 109.

${ }^{25}$ TOVEY, 2014, p. 10.

${ }^{26}$ KICKHÖFEL, Oswaldo. Notas para uma História da Igreja Episcopal Anglicana do Brasil. Porto Alegre: Projeto Memória, 1995. p. 95. 
Em circunstâncias normais, e na maioria das paróquias urbanas, esperava-se que a Confirmação acontecesse pelo menos uma vez por ano. As aulas de Confirmação seriam compostas, em sua maioria, por jovens no início da adolescência, que, após um período de catequese, afirmariam sua fé na presença de um bispo ${ }^{27}$ e receberiam dele a imposição de mãos. Depois da Confirmação, essas pessoas seriam admitidas à Comunhão pela primeira vez.

No entanto, ao longo do século XX, alguns sinais de mudança de interpretação passaram a ser vistos entre anglicanos brasileiros. Por exemplo, ficava claro, em certos documentos, que a Confirmação era vista como um sacramento por certas pessoas ${ }^{28}$, sendo citada como um sacramento menor ou como um rito sacramental. Além disso, o uso do crisma foi restaurado por alguns bispos. Essas mudanças indicavam claramente uma influência gradual do anglo-catolicismo, uma visão mais elevada do rito, uma teologia que fazia referência a "aumentar e fortalecer no Espírito" e um certo alinhamento às práticas que poderiam ser encontradas em outras partes da Comunhão Anglicana.

O LOC 1984 pretendia introduzir uma teologia do Batismo mais forte, mais parecida com o LOC 1979 da Igreja Episcopal e outras partes da Comunhão Anglicana. ${ }^{29}$ Batismo foi claramente descrito como rito de iniciação plena na vida da igreja, ${ }^{30}$ então a Comunhão imediatamente após o Batismo passou a ser encorajada (até mesmo para bebês). O rito preconizava um sinal da cruz na fronte de cada pessoa batizada depois do banho. As rubricas faziam referências explícitas de que o crisma poderia ser usado para tal sinal da cruz. Além disso, uma vela deveria ser dada a cada pessoa batizada. ${ }^{31}$

A Confirmação foi oferecida como uma "reafirmação pública da fé, de votos e promessas batismais, com a imposição de mãos por um bispo" 32 . Rubricas sugeriram a possibilidade de usar o Rito de Confirmação do LOC 1984 como reafirmação dos votos batismais, mas as únicas opções que receberam orações claras e responsos específicos Confirmação e recepção. O bispo oraria inicialmente para que cada pessoa fosse renovada e fortalecida para o trabalho cristão, pelo poder do Espírito. ${ }^{33} \mathrm{O}$ bispo continuava e impunha as mãos sobre cada pessoa a ser confirmada, com duas opções de orações que invocavam o Espírito Santo para fortalecer ou proteger cada pessoa a ser confirmada (a fim de que pudessem crescer no Espírito). As pessoas a serem recebidas teriam um aperto de mão (as rubricas mencionavam que o bispo cumprimentaria a mão direita da pessoa) e uma afirmação (não uma oração), admitindo-as na comu-

\footnotetext{
27 À época, só havia bispos do sexo masculino.

28 SIMÕES, Plínio Lauer. Nosso Lugar no Cristianismo e Nossa Relação com Outras Religiões. In: SIMÕES, Plínio Lauer (Org.). A Igreja Episcopal no País do Futuro. Porto Alegre: Eclésia, 1960. p. 54-55.

29 FORRESTER, Duncan B.; GAY, Doug. Worship and Liturgy in Context: Studies and Case Studies in Theology and Practice. London: SCM, 2009. p. 200-201.

${ }^{30}$ IGREJA EPISCOPALANGLICANA DO BRASIL. Livro de Oração Comum da Igreja Episcopal Anglicana do Brasil. Porto Alegre: Metrópole, 1984. p. 162.

31 IGREJA EPISCOPAL ANGLICANA DO BRASIL, 1984, p. 169-171.

32 IGREJA EPISCOPAL ANGLICANA DO BRASIL, 1984, p. 174.

33 IGREJA EPISCOPAL ANGLICANA DO BRASIL, 1984, p. 180.
} 
nhão "desta Igreja" 34 . Uma oração final, mais uma vez, seria feita para que o Espírito guiasse e protegesse tais fiéis.

O rito de 1984 afirmava claramente que se tratava de uma afirmação madura da fé. No entanto, suas orações e sua linguagem reviveram conceitos que surgiram durante a Idade Média, da Confirmação como uma espécie de "fortalecimento" no Espírito e "preparação para a batalha". Como não era mais um passo necessário para a primeira comunhão, a idade para Confirmação de adolescentes batizados na primeira infância gradualmente aumentou. Contudo, uma coisa permaneceu altamente incontestável: a Confirmação continuou a ser vista como um ato estritamente episcopal, com a explicação de que, como o ofício do bispo é apostólico, a presença de um bispo como presidente simboliza a presença de toda a igreja cristã. ${ }^{35}$

\section{Práticas de Confirmação atuais no Brasil, seus desafios e incoerências}

Em 2015, um novo Livro de Oração Comum foi lançado, que efetivamente manteve alguns dos princípios adotados em 1984. O Batismo permaneceu como sacramento completo da iniciação cristã, e a Confirmação foi efetivamente descrita como uma "reafirmação pública e consciente de fé, das promessas e dos votos batismais e [...] a imposição das mãos do(a) bispo(a)"36. Aquelas pessoas que foram batizadas como bebês deveriam ser confirmadas "como um passo natural de uma vida cristã madura”. O LOC também recomenda que pessoas adultas a serem batizadas devem ser confirmadas imediatamente.

Uma grande diferença entre o LOC 2015 e o LOC 1984 é que os Ritos de Iniciação Cristã são agora agrupados em um único conjunto de liturgias: 1) Batismo, 2) Confirmação e Recepção, e 3) uma celebração conjunta do Batismo, Confirmação e Recepção.

$\mathrm{O}$ rito de Confirmação começa com um chamado à oração, que afirma claramente que as pessoas que devem ser confirmadas (ou recebidas) estão dispostas a assumir um compromisso mais profundo com Cristo e renovar seus votos batismais. ${ }^{37}$. Isso enfatiza um entendimento teológico mais parecido com o dos reformadores, ligando a Confirmação a uma afirmação madura da fé. O mesmo entendimento é replicado quando as pessoas que devem ser confirmadas (ou recebidas) renunciam ao mal e se comprometem a afirmar a aliança batismal. ${ }^{38}$

Em geral, os ritos de confirmação no LOC de 2015 são mais leves no tocante à linguagem medieval de "preparação" e "proteção", mas alguns desses elementos podem ser encontrados. Três orações atestam esse conceito teológico: a coleta que a pessoa que preside faz após as Intercessões (e que se aplica a todas as pessoas que estão sendo confirmadas e/ou recebidas), e as duas opções de orações que seguem a im-

${ }^{34}$ IGREJA EPISCOPAL ANGLICANA DO BRASIL, 1984, p. 181.

35 BARROS, Saulo Maurício de. Introdução à Liturgia. Porto Alegre: Centro de Estudos Anglicanos, 2006.

${ }^{36}$ BARROS, 2006, p. 547

37 BARROS, 2006, p. 564.

38 BARROS, 2006, p. 568. 
posição das mãos sobre as pessoas que estão para ser confirmadas. Para as pessoas que serão recebidas em comunhão, a mesma saudação encontrada no LOC 1984 é dita.

As rubricas também deixam explicitamente claro que o(a) bispo(a) é o(a) principal presidente de toda a liturgia. Ao longo do rito de confirmação e recepção ${ }^{39}$, as rubricas sempre se referem a "bispo(a)" quando se trata do papel de quem preside. O bispo é aquele que coloca as mãos nos confirmandos e alcança a mão direita para saudar quem quer que seja recebido. Enquanto as rubricas do Batismo deixam claro que os recém-batizados podem ser ungidos com crisma quando um sinal da cruz é feito na testa, não há rubricas específicas sobre o uso do crisma para a Confirmação. Seu uso não é explicitamente validado por qualquer LOC brasileiro.

Curiosamente, o LOC 2015 contém um rito de Renovação de Votos de Ordenação na Quinta-Feira Santa, com bênção obrigatória de óleos para os enfermos, e crisma, e uma bênção opcional do óleo de catecúmenos(as). Isso reflete uma realidade que existe em algumas comunidades, onde a pessoa que preside irá ungir catecúmenos(as) antes do Batismo, mesmo que não explicitamente declarado nas rubricas. A bênção do óleo do crisma, no entanto, é obrigatória. Isso porque o LOC 2015 preconiza seu uso no Batismo, restituindo seu lugar central após o banho com água. Por isso o Batismo no LOC 2015 menciona seu uso explicitamente nas rubricas.

O Livro de Oração Comum não indica quem deve ser confirmado(a) e quem deve ser recebido(a) na Igreja Episcopal Anglicana do Brasil. Entretanto no Cânon 12, Artigo 50 dos Cânones Gerais da IEAB, está descrito que "são membros confirmados da IEAB todas as pessoas que receberam o sacramento da confirmação, segundo o uso e preceitos do Livro de Oração Comum, e todas aquelas que, confirmadas por bispos(as) de sucessão apostólica, sejam devidamente recebidas em comunhão por um(a) bispo(a) da IEAB" 40 .

A prática atual, se comparada a textos litúrgicos e canônicos, levanta algumas questões, que indicam claramente como as visões conflitantes da Confirmação ainda coexistem dentro da IEAB, sem uma prática clara e uniforme. Por exemplo:

- O LOC 2015 enfatiza claramente duas teologias principais da Confirmação: uma de afirmação madura da fé seguida pela imposição de mãos por um(a) bispo(a), que foi bem desenvolvida pelos reformadores ingleses; e outra de aumento da Graça e fortalecimento pelo poder do Espírito Santo, através de orações feitas por um(a) bispo(a). É claro, a partir do texto litúrgico, que se trata de uma renovação consciente dos votos batismais. Um aumento de Graça, pelo poder do Espírito, é visto como consequência de um processo de santificação que flui da aliança batismal, e não de uma "mágica" imposição de mãos. Entretanto, isso não tem sido prática comum em alguns lugares, que ainda atribuem à Confirmação o conceito de "recepção" do Espírito Santo, ou mesmo "completude" do Batismo.

- Em nenhum lugar do LOC, o óleo do crisma é mencionado quando se trata de Confirmação, desatrelando a teologia do livro de uma compreensão escolástica da Confirma-

\footnotetext{
39 The same applies to the combined rite of Baptism, Confirmation and Reception

40 IGREJA EPISCOPAL ANGLICANA DO BRASIL. Cânones Gerais da Igreja Episcopal Anglicana do Brasil. São Paulo: IEAB, 2016. p. 12.
} 
ção como sacramento transmitido através da unção com óleo. Uma mera imposição de mãos é suficiente. Por outro lado, o rito do Batismo abre espaço para uma unção com crisma ao selar a fronte de recém-batizados, marcando tais pessoas como de Cristo. O óleo do crisma é visivelmente considerado mais importante que o óleo dos catecúmenos, por exemplo, uma vez que deve ser consagrado todos os anos pelo(a) bispo(a) e distribuído às paróquias. A prática atual indica que seu uso é amplo em Batismos. Entretanto, seu uso em confirmações ainda existe, e até mesmo esperado por algumas comunidades (ainda que não previsto na rubrica do LOC).

- O Batismo é claramente considerado como plena e completa iniciação na vida da igreja. O selo na fronte da pessoa batizada (com ou sem crisma) marca a conclusão do rito batismal, sem qualquer necessidade razoável de outra cerimônia para "terminá-lo". O rito batismal do LOC 2015 restaura o padrão da igreja nos séculos IV e V, unificando assim o Batismo, selo (com ou sem óleo do crisma) e primeira comunhão em um único fluxo. - Além de alguns detalhes canônicos sobre funções específicas para pessoas confirmadas, e vocação para o ministério ordenado, membros batizados são totalmente incluídos na vida da IEAB e são bem-vindos à Mesa do Senhor. Para pessoas comuns, a Confirmação não é necessária em termos práticos. Tornou-se uma espécie de formalidade para marcar seus membros tornando-os membros da igreja, ou uma cerimônia de graduação cristã para a idade adulta. É preciso, então, haver uma teologia da Confirmação mais clara e unificada para ser comunicada às pessoas.

- Os cânones da IEAB referem-se à Confirmação como um sacramento (e, por mais que eu me satisfaça com uma visão elevada dos sacramentos, deve-se argumentar que essa não é uma visão uniforme no anglicanismo). Em contraste, o cânon do Sagrado Matrimônio não possui referências ao mesmo enquanto sacramento.

- $\mathrm{O}$ direito canônico também indica que somente aquelas pessoas que foram confirmadas por bispos(as) em sucessão apostólica podem ser recebidas por um bispo da IEAB. No entanto, a prática comum raramente segue essa regra. Desde o advento das reformas litúrgicas que se seguiram ao Movimento Litúrgico e ao Concílio Vaticano II, católicos romanos têm sido geralmente confirmados por um sacerdote. As igrejas orientais sempre confiaram nos padres para selarem com óleo do crisma após o Batismo e, como nessas igrejas a maioria dos Batismos é infantil, na prática, os ortodoxos recebem a crismação logo após o Batismo (infantil). A prática atual em várias paróquias da IEAB é receber tanto católicos romanos quanto ortodoxos que foram confirmados sem perceber que - muito provavelmente - foram confirmados por um padre (e no caso de ortodoxos, uma "pedoconfirmação")!

- É senso comum entre liturgistas contemporâneos que a obrigação de ter um(a) bispo(a) presidindo cada Confirmação é um costume que só existia na Roma antiga e que foi gradualmente levado para a cristandade ocidental. Gerações de cristãos e cristãs foram confirmadas por presbíteros (e ainda o são, na ortodoxia e, agora, no catolicismo romano). A Consulta Internacional de Litúrgica Anglicana já declarou seu consenso sobre a validade das Confirmações realizadas por sacerdotes. De fato, em sua declaração sobre a Iniciação Cristã, sugeriu que ela poderia "ser delegada pelo(a) bispo(a) a um(a) presbítero(a)". Existe espaço para a Confirmação por sacerdotes no anglicanismo? Ou o(a) bispo(a) deve permanecer como presidente principal por outras razões teológicas? - Como o LOC não menciona quem deve ser recebido(a), parece que existem dois padrões em prática. Daquelas pessoas a quem comumente destinamos à Confirmação espera-se que façam uma afirmação madura de fé e recebam a imposição de mãos de um(a) bispo(a) para fortalecimento no Espírito Santo, como o rito do LOC declara. Já 
para aquelas pessoas que destinamos à recepção, devem ser previamente confirmadas por um(a) bispo(a) em Sucessão Apostólica, que é o que os Cânones dizem. Não há referências explícitas a uma afirmação de fé nesses casos. Uma pessoa convertida do metodismo, luteranismo ou presbiterianismo, por exemplo, que passou por uma reafirmação adulta dos votos batismais em sua antiga igreja e que sempre foi cristã e comprometida, é obrigada a ser confirmada porque sua afirmação de fé não teve imposição de mãos de um(a) bispo(a) em sucessão apostólica. No entanto, alguém que foi batizado(a) e crismado(a) por sacerdote ordenado por bispo em sucessão apostólica (caso de católicos romanos e ortodoxos), acaba por ser recebida no meio da IEAB, sem uma re-Confirmação. A letra dos cânones, contudo, reforça que - em tese - tais pessoas teriam que ser confirmadas, uma vez que não foram "confirmadas por bispos(as) de sucessão apostólica, sejam devidamente recebidas em comunhão por um(a) bispo(a) da IEAB”. Foram confirmadas por padres, às vezes na primeira infância.

\section{Seguindo em frente: propostas para uma teologia consistente e coerente da Confirmação}

Neste ponto, é importante mencionar que a Confirmação provavelmente não desaparecerá - pelo menos não no futuro próximo. Independentemente de um entendimento emergente entre liturgistas acerca das muitas inconsistências que podem ser encontradas em termos de práticas de Confirmação em igrejas anglicanas (e também em outras cristãs), tal rito é muito querido pelos fiéis para ser abolido. No entanto, é possível propor uma série de medidas que assegurem uma teologia coerente e não enfraqueçam o papel do Batismo na vida da igreja.

1. Primeiro de tudo, é muito mais fácil prometer mudanças canônicas em vez de mudar um LOC que acaba de ser lançado. Portanto as emendas devem ser feitas ao direito canônico, e não ao LOC (o que parece razoável, já que os textos canônicos de confirmação são os mais problemáticos, não o rito do LOC).

2. As referências canônicas à Confirmação como um sacramento devem ser removidas, pois não refletem um entendimento uniforme no anglicanismo. É possível argumentar que aí há uma natureza sacramental, é claro, mas tal discussão não pertence ao direito canônico.

3. O LOC entende que um(a) bispo(a) deve ser presidente principal em Confirmações e/ou Recepções. Isso deve ser interpretado muito mais como uma medida pastoral do que teológica, uma vez que não há precedente histórico para justificar a necessidade explícita de bispo(a) para que as Confirmações sejam válidas. No entanto, em nossa tradição, as Confirmações e/ou Recepções são momentos em que as comunidades da igreja encontram o(a) bispo(a) local e são frequentemente momentos altamente festivos. Assim, ainda que o anglicanismo tenha se tornado o único ramo principal do cristianismo a manter essa prática, ela claramente encontrou seu lugar no coração dos fiéis (e, é claro, também no dos bispos e bispas). Entretanto, em certos casos específicos (como o Batismo de pessoa adulta, que deve ser seguido pela Confirmação), sacerdotes poderiam ser 
autorizados(as) a confirmar, com a autorização do(a) bispo(a), se ele(a) não puder estar presente.

4. Visto que é claro que as Confirmações podem ser válidas sem serem presididas por um(a) bispo(a), referências canônicas à validade dos ritos de Confirmação realizados em outras igrejas devem remover todas as referências ao episcopado. O texto canônico atual contradiz altamente a prática corriqueira de meramente receber (sem re-Confirmar) muitos ex-católicos romanos (e ortodoxos) que foram confirmados/crismados por padres, o que indica um reconhecimento tácito de confirmação por presbíteros como algo válido.

5. O LOC de 2015 deixa muito claro que o Batismo é o rito completo da iniciação na vida cristã. A restauração do selo com o sinal da cruz na fronte (que pode e deve ser feito com óleo do crisma) imediatamente após o Batismo realinha esse rito com a tradição mais antiga da igreja e fornece um encerramento necessário ao rito batismal, que leva imediatamente à primeira Comunhão das pessoas recém-batizadas, independente de sua idade.

6. Portanto a Confirmação não deve ser vista como um segundo passo que "aperfeiçoa e finaliza" o Batismo, razão pela qual o uso do óleo do crisma não é apropriado para as Confirmações. A Confirmação precisa ser definida mais claramente como uma "afirmação madura da fé e um compromisso público com o Senhor”, após o qual o(a) Bispo(a) (na maior parte dos casos) oferece sua bênção através da imposição de mãos. Uma consequência natural de abraçar a fé e o compromisso com Jesus, é claro, é o aumento da Graça e o fortalecimento no Espírito Santo, e é por isso que o rito sugere explicitamente tais efeitos em orações e petições. Essa compreensão da Confirmação cria uma teologia mais fundamentada, que fornece um raciocínio para manter a tradição cristã ocidental em mantê-la como um rito separado do Batismo, sem diminuir a centralidade do Batismo na vida de cada cristão ou cristã.

7. Também, de acordo com essa compreensão emergente da Confirmação, que é centrada em torno de um compromisso maduro com Cristo e uma renovação dos votos batismais, é possível sugerir que cristãos e cristãs que já fizeram uma afirmação pública da fé (baseada no credo dos Apóstolos - o símbolo batismal suficiente) poderiam ser recebidas como anglicanos(as), em vez de (re)confirmadas. Essa afirmação pública e madura da fé deve ser, idealmente, acompanhada pela imposição de mãos, que é um gesto ritual que incorpora o papel do Espírito Santo, como ação sacramental. Não obstante, é possível argumentar que somente a afirmação madura da fé já contém a essência acordada do significado do rito para nossos tempos, e poderia ser o elemento unificador básico para definir o que é necessário para alguém ser recebido como anglicano, em vez de confirmado.

8. Finalmente, futuras comissões litúrgicas poderiam examinar a natureza e propósito do rito de Confirmação como um todo. Algumas propostas plausíveis de discussão entre liturgistas são: renomear o rito de Confir- 
mação como “Afirmação de Fé”, e utilizar a imposição de mãos tanto em pessoas a serem confirmadas quanto recebidas. Contudo, tais estudos devem amadurecer e conformar-se a acordos mútuos entre liturgistas locais, organismos da igreja e um consenso mais amplo na Comunhão Anglicana.

Com base nessas propostas, deixo uma sugestão de uma possível reescrita do Canon 12, Artigo 50 dos Cânones da IEAB:

“Art. 50. São membros confirmados da IEAB todas as pessoas que receberam a Confirmação, segundo o uso e preceitos do Livro de Oração Comum, e todas aquelas que, havendo já realizado em outras igrejas cristãs uma afirmação prévia e madura da fé cristã baseada nos credos históricos, sejam devidamente recebidas em comunhão por um(a) bispo(a) da IEAB.

Parágrafo único - Sob circunstâncias específicas, e com explícito consentimento da autoridade eclesiástica, um(a) presbítero(a) poderá realizar Confirmações."

\section{Conclusão}

A IEAB evoluiu em termos da compreensão do sacramento do Batismo. Pelo menos desde os anos 1980, o Batismo foi reentendido como porta de entrada para a plena inclusão na Igreja de Cristo. A Confirmação, no entanto, não teve uma definição melhor desde então. O Livro de Oração Comum de 2015 sugere ligá-la a uma afirmação madura da fé, mas os Cânones da Igreja e a prática comum apresentam visões conflitantes.

Este artigo buscou apresentar alguns dos desafios atuais em relação à prática da Confirmação entre anglicanos(as) no Brasil, sugerindo assim implementar uma teologia unificada da Confirmação que reforce a centralidade do Batismo, reconheça as declarações mútuas entre organismos anglicanos e abrace as necessidades pastorais das comunidades locais.

\section{Referências}

AUSTIN, Gerard. Anointing With the Spirit: The Rite of Confirmation, the Use of Oil and Chrism. Collegeville: Liturgical Press, 1985.

BARROS, Saulo Maurício de. Introdução à Liturgia. Porto Alegre: Centro de Estudos Anglicanos, 2006.

DEISS, Lucien. Springtime of the Liturgy. Collegeville: Liturgical Press, 1967.

FERGUSON, Everett. Baptism in the Early Church: History, Theology, and Liturgy in the First Five Centuries. Grand Rapids: Eerdmans, 2013.

FORRESTER, Duncan B.; GAY, Doug. Worship and Liturgy in Context: Studies and Case Studies in Theology and Practice. London: SCM, 2009.

HILL, John W. B.; ROPPELT, Rowena. Christian Initiation in the Anglican Communion. Anglican Theological Review, New York, n. 3, p. 419-34, 1995.

IGREJA EPISCOPAL ANGLICANA DO BRASIL. Cânones Gerais da Igreja Episcopal Anglicana do Brasil. São Paulo: IEAB, 2016.

IGREJA EPISCOPALANGLICANA DO BRASIL. Livro de Oração Comum da Igreja Episcopal Anglicana do Brasil. Porto Alegre: Metrópole, 1984. 
IGREJA EPISCOPALANGLICANA DO BRASIL. Livro de Oração Comum da Igreja Episcopal Anglicana do Brasil. Porto Alegre: Paulus, 2015.

INTERNATIONAL ANGLICAN LITURGICAL CONSULTATION. The Toronto Statement: Walk in Newness of Life -the findings of the fourth International Anglican Liturgical Consultation. Toronto: ACC, 1991.

JOHNSON, Maxwell E. The Rites of Christian Initiation. Collegeville: Liturgical Press, 2007. KICKHÖFEL, Oswaldo. Notas para uma História da Igreja Episcopal Anglicana do Brasil. Porto Alegre: Projeto Memória, 1995.

TOVEY, Philip. Anglican Confirmation 1662-1820. Oxford: Routlege, 2014.

TURRELL, James F. Celebrating the Rites of Initiation. New York: Church Publishing, 2013. SIMÕES, Plínio Lauer. Nosso Lugar no Cristianismo e Nossa Relação com Outras Religiões. In: SIMÕES, Plínio Lauer. (Org.). A Igreja Episcopal no País do Futuro. Porto Alegre: Eclésia, 1960. p. 46-58.

SENN, Frank. Introduction to Christian Liturgy. Minneapolis: Augsburg, 2012.

STEVENSON, Kenneth. The Mystery of Baptism in the Anglican Tradition. Harrisburg: Morehouse, 1998.

WEIL, Louis. Liturgical Sense. New York: Seabury, 2013.

WHITAKER, E. C. Documents of the Baptismal Liturgy. Revised and expanded by Maxwell E. Johnson. Collegeville: Liturgical Press, 2003. 